\title{
A mobilidade como aventura na cidade: jogos base- ados em geolocalização (gps) e apropriação urbana.
}

\author{
Juliana Alencar Viana *
}

\begin{abstract}
Resumo. Este artigo propõe reflexões sobre a relação de uma nova modalidade de jogo e o espaço público por meio de práticas culturais que utilizam tecnologias dos dispositivos móveis. Ao tecer relações interdisciplinares entre o campo do lazer, os estudos da comunicação e do espaço, buscou-se reconhecer experiências, para além do mero consumo do discurso ecologicamente correto e/ou da utilidade da atividade física como promotora de hábitos saudáveis, inserindo os jogos urbanos de mobilidade, como práticas culturais que estabelecem a partilha de experiência, apontando novas formas de sociabilidade e de apropriação urbana como lazer na contemporaneidade.

Palavras-chave: Atividades de Lazer. Cidades. Jogos e brinquedos.
\end{abstract}

\section{INTRODUÇÃo}

Sem que se possa aprofundar isto aqui, pode-se dizer que o interesse culinário, o jogo das aparências, os pequenos momentos festivos, as perambulações diárias e o lazer não podem ser mais vistos como elementos sem importância ou frívolos da vida social. (MAFFESOLI, 2005, p. 12)

Devido a uma aproximação com o campo do lazer, procuro traçar relações deste com o cenário urbano, compreendido como campo de jogo, para algumas práticas culturais advindas pelas tecnologias da informação e comunicação, o que acaba por ressignificar o entendimento moderno de cidade.

Nesse sentido, as cidades modernas foram atravessadas, historicamente, por um urbanismo que elevou o lazer ao patamar de uma função urbano-social. Tal função carregava um reforço científico,

* Mestre em Lazer. Licenciada em Educação Física. Pesquisadora do Laboratório de Pesquisa sobre Formação e Atuação Profissional em Lazer (Oricolé). Universidade Federal de Minas Gerais, Belo Horizonte, MG, Brasil. E-mail: gaiajones@gmail.com 
devido aos saberes em ascensão, como fisiologia, a higiene e mais tarde, a psicologia social (a partir de 1940), que promulgava ações de melhoria da saúde pública por meio de procedimentos higiênicos aplicados ao corpo e à mente dos trabalhadores (NIEMEYER, 2002). Dessa forma, especialmente a Higiene Social, atuava na prevenção, correção, controle dos corpos, aplicados para garantir a normalidade social. É dentro desse contexto que surgem, por exemplo, os parques infantis, espaço planejado nas cidades e destinado às crianças, comportando aí o que alguns autores denominam de pedagogias do corpo (FRAGA, 2006a).

Nesse mesmo período, cabe registrar o surgimento, na literatura especializada do século XIX, da palavra stress, como uma força adversa e incontrolável a afetar o citadino, sendo associado frequentemente com a vida nas sociedades urbanas. A Higiene Social, portanto, integra-se ao urbanismo, requalificando parques públicos e uma nova ordem urbana como antídoto aos rigores da urbanização, incentivando práticas de lazer ao ar livre com aspecto funcional de promoção da saúde e higiene, segundo Niemeyer (2002).

Já na contemporaneidade, acerca da relação dos sujeitos com a cidade, Maffesoli (2001, p. 22) questiona: “[...] será que o drama contemporâneo não vem do fato de que o desejo de errância tende a ressurgir como substituição, ou contra o compromisso de residência que prevaleceu durante toda a modernidade?" Para o autor, a produção, os costumes, a saúde, a educação e tudo o mais que se convencionou chamar de "social" foi domesticado, assentado no trabalho e destinado à residência, pela modernidade, pois, domesticar significa(va) fixar e, com isso, a possibilidade de dominar. Da mesma forma, o lazer na cidade sofreu um processo de domesticação, pela elevação dos shoppings e demais equipamentos de lazer como espaços destinados à ocupação do tempo livre, de maior controle por meio do consumo e do entretenimento.

É a partir do desenrolar desse cenário moderno que, hoje, no imaginário social, as práticas de lazer ao ar livre são cogitadas como mecanismo duplamente útil: como atividade física, de promoção de uma vida saudável, de reabilitação dos males da vida urbana e pela

Movimento, Porto Alegre, v. 17, n. 01, p. 237-251, janeiro/março de 2011. 
ação politicamente correta para com os recursos naturais, designada especialmente pelos prefixos "eco" e conceito de sustentabilidade, ao mesmo tempo em que representa um nicho de mercado para a indústria cultural, compreendido dentro do denominado "lazer ativo" (FRAGA, 2006b).

De outra forma, Villaverde (2003) afirma que a mobilidade, característica também presente na experiência turística, pode ser pensada pela teia de relações construídas e não somente pela dimensão do consumo. Por mais que o ecoturismo seja encarado pela ótica da indústria cultural e pela atividade saudável, é preciso pensar na construção das subjetividades que tais experiências propiciam.

Dessa forma, a exacerbação moderna de lugar(es) renovou e atualizou o desejo por novas errâncias, já que aquilo que se move escapa à câmera sofisticada do panóptico (BENTHAM, 2008) ou, ao menos, subverte a lógica dos espaços, apontando desvios possíveis por meio das próprias ferramentas de domesticação e controle.

Nesse cenário, as tecnologias da informação e comunicação da era digital, especialmente os dispositivos móveis, permitem a pulverização de tecnologias nômades, na promoção e partilha de errâncias que testemunham um enriquecimento cultural ligado à mobilidade e às relações, nos espaços online e offline. Aqui, comunicação é mobilidade, significa deslocar-se, representando novos modos de estar junto. A errância, por sua vez, seria uma expressão de uma outra relação com o outro e com o mundo, menos ofensiva, mais carinhosa, um tanto lúdica (MAFFESOLI, 2001) e se torna mecanismo de socialização. Segundo o autor, a mobilidade carrega uma dose de aventura, já que, para ele, existir é sair de si, é um modo de se abrir ao mundo e aos outros. Não é por acaso que o gênero "aventura" esteja presente nos desenhos animados ${ }^{1}$, obras da literatura ${ }^{2}$ e do cinema ${ }^{3}$, atraindo crianças, jovens e adultos, expressando em números a marca de um público fiel. ${ }^{4}$

\footnotetext{
${ }^{1}$ Caverna do Dragão.

${ }^{2}$ Alice no país das maravilhas.

3.Mágico de Oz, Indiana Jones, O Senhor dos Anéis.

${ }^{4}$.São mais 76 mil títulos de filmes do gênero aventura cadastrados no IMBD - Internet Movie Database, sendo o gênero mais produzido no cinema: http://www.imdb.com/
}

Movimento, Porto Alegre, v. 17, n. 01, p. 237-251, janeiro/março de 2011. 
Dessa maneira, mais do que pensar a atividade física na natureza e o esporte de aventura restrito à dimensão da saúde, interessa a este trabalho trazer ao debate os tipos de relações estabelecidas nestas experiências, a partir da mobilidade, seja no espaço urbano ou "natural". Assim, surgiram algumas questões que nortearão este trabalho: é possível a aventura na cidade por meio das tecnologias da informação e comunicação? Qual o tipo de aventura elas proporcionam? De que formas as tecnologias nômades podem contribuir para uma aventura urbana? São provocações que instigam novos diálogos, dada as práticas de desvio na relação com a cidade contemporânea.

Este trabalho pretende retomar algumas reflexões sobre o espaço público por meio de práticas corporais urbanas que utilizam tecnologias nômades, advindas dos dispositivos móveis. Além disso, busca reconhecer experiências para além do mero consumo de discursos politicamente corretos e/ou a utilidade da atividade física como promotora de hábitos saudáveis, percorrendo práticas culturais que estabelecem a partilha de experiências como vetores de subjetivação, de relação, portanto, de novas sociabilidades. Para tal, recorro à produção multidisciplinar e de intersecção do campo do lazer com os estudos da comunicação e do espaço para elaborar este ensaio. Poucos estudos têm operado na lógica interdisciplinar entre as referidas áreas. Com isso, espera-se que este trabalho possa ampliar diálogos entre estas produções, já que contribuem para compreender fenômenos culturais em toda a sua complexidade.

Portanto, o compromisso ético-político de descortinar transformações socioculturais qualitativas e ampliar eventuais demonstrações de resistências às lógicas e à subjetividade dominantes, inclusive no contexto da atividade turística, deve, em minha opinião, ser assumido. Mesmo havendo uma notável incorporação destas práticas corporais pela lógica mercadológica turística ou esportiva, tal incorporação nunca é total, assim como nunca é total o enquadramento da subjetividade pelos poderes vigentes e dominantes, tal como têm demonstrado Foucault, Deleuze e Guattari, devendo-se ir em busca de "resistências moleculares", de pequenas "brechas", de "linhas de fuga", subjacentes a essas experiências humanas. (VILLAVERDE, 2003, p. 68)

Wovimento, Porto Alegre, v. 17, n. 01, p. 237-251, janeiro/março de 2011. 
Seguindo esta lógica e interessada pela errância urbana, termo bastante explorado por Jacques (2006), é que corroboro com Villaverde (2003), ao enfatizar que, as noções de amizade, cortesia, solidariedade, hospitalidade e respeito no espaço público deveriam compor o quadro referencial de qualquer forma de vida e prática social humana, em especial o lazer e a atividade turística.

\title{
2 CiDADES, TECNOLOgIAS NÔMADES E MOBILIDADE
}

As profundas mudanças sofridas pelas cidades modernas devido aos processos de privatização e mercantilização contribuíram, paulatinamente, para o desaparecimento do ambiente público, o que traz como consequência o desaparecimento da vida urbana.

\begin{abstract}
A domesticação moderna das culturas se dissolve, as práticas culturais migram de seus locais habituais, se difundindo no espaço virtual da mídia. Essa midialização estimula a tendência de privatizar os eventos culturais originalmente públicos e sua percepção estética. Com isso reforça ainda mais a erosão progressiva dos ambientes públicos urbanos. (PRIGGE, 2002, p. 55)
\end{abstract}

Dialogando com o autor, as tecnologias serviram e servem à permanência e conforto dos espaços privados, contudo, desvios e (re)apropriações do espaço público também se multiplicam em virtude dessas mesmas tecnologias. A inserção das tecnologias da informação e comunicação (TICs) inaugurou também novas formas de viver o urbano e a natureza, principalmente pelo avanço da cibercultura: o acesso, a conexão e formação de redes sociais (LEMOS, 2004).

Segundo Lemos (2009, p.28), “[...] os estudos de comunicação têm investido em análises sobre empresas de comunicação, estudos de recepção, consumo das mídias, mas muito pouco sobre a relação entre comunicação, espacialização e mobilidade". A mobilidade produz espacialização e os lugares devem ser pensados como eventos em um fluxo de práticas sociais, de processos territorializantes e desterritorializantes (LEMOS, 2009), o que pode reforçar uma

Movimento, Porto Alegre, v. 17, n. 01, p. 237-251, janeiro/março de 2011. 
experiência narrativa do espaço físico, o que fortalece a dimensão da experiência do contexto, do local, dentro de um fenômeno mundial. Assim, a mobilidade deve ser vista como produto cultural e oferece uma oportunidade para usos e apropriações do espaço para diversos fins (lazer, comerciais, políticos, policiais, artísticos).

Para Lemos (2007b) estamos vivendo o avanço da cibercultura em direção ao "Dispositivo Híbrido Móvel de Conexão Multirredes", pois, para ele: o que chamamos de telefone celular é um dispositivo (um artefato, uma tecnologia de comunicação); híbrido, já que congrega funções de telefone, computador, máquina fotográfica, câmera de vídeo, processador de texto, GPS, entre outras; móvel, isto é, portátil e conectado em mobilidade funcionando por redes sem fio digitais, ou seja, de conexão; e multirredes, já que pode empregar diversas redes, como: bluetooth e infravermelho, para conexões de curto alcance entre outros dispositivos; celular, para as diversas possibilidades de troca de informações; internet (wi-fi) e redes de satélites para uso como dispositivo GPS.

Segundo o Comitê Gestor da Internet no Brasil (2009) e o Centro de Estudos sobre as Tecnologias da Informação e da Comunicação no país, a proporção de domicílios que possuem telefone fixo alcança a porcentagem de $44 \%$ e de telefone celular atinge cerca de $82 \%$. Esses números nos indicam que a comunicação por tais dispositivos está em progressão - seja pela facilitação ao seu acesso, seu caráter híbrido ou pela mobilidade - e está superando, inclusive, as tecnologias de comunicação fixas, de menor funcionalidade e interatividade.

A esse respeito, algumas práticas corporais urbanas têm se utilizado destes dispositivos e desenhado na cidade os chamados wireless street games (PEREIRA JUNIOR, 2006; LEMOS, 2008). Vale à pena dizer que existem inúmeros jogos possíveis pelos dispositivos móveis dos quais exige alguma mobilidade para a sua realização, ou seja, tais jogos promovem experiências no espaço urbano e representam desvios à lógica planejada da cidade.

De acordo com Santos (2002), o espaço público se transforma em espaço crítico na medida em que é questionado pelo ciberespaço.

Movimento, Porto Alegre, v. 17, n. 01, p. 237-251, janeiro/março de 2011. 
Essa prática crítica, denominada pelos situacionistas de deriva, leva a reflexão sobre o espaço público, em diálogo com o ambiente virtual, já que tais jogos operam com territorialização e desterritorialização, transformando num espaço híbrido (LEMOS, 2007a) implodindo oposições clássicas. Maffesoli (2005, p. 73), afirma que a estética, como "[...] cultura dos sentimentos, simbolismo, ou, para empregar uma expressão mais moderna, como lógica comunicacional, garante a conjunção de elementos até então separados".

\begin{abstract}
Nesse sentido é que o espaço pode ser uma base de exploração. Aquilo que em compensação o torna flutuante, nebuloso, quase imaterial. É isso que, na esteira dos surrealistas, os "situacionistas" dos anos 60 tinham percebido muito bem praticando o que chamavam de deriva urbana ou a "psicogeografia". A cidade era, desde então, um terreno de aventura, em que o lúdico e o onírico tinham um lugar especial. Aventura que era um modo de viver experiências de toda ordem, de suscitar encontros, de fazer da existência uma espécie de obra de arte. (MAFFESOLI, 2001, p. 88)
\end{abstract}

Para ele, seria um situacionismo geral todo esse interesse pelo presente, em oposição à regularidade do trabalho e da família, prevalecendo um tempo de desengajamentos, um tempo de instantes sucessivos, de sinceridades sucessivas, um tempo em que organizam-se grupos efêmeros, interessados na qualidade da participação sem a obsessão da continuidade. Esse apetite comunicacional não resulta unicamente do desenvolvimento tecnológico, pois seu valor encontra-se na experiência partilha na qual funciona como vetor de criação.

Os jogos urbanos com dispositivos móveis poderiam, portanto, agregar às experiências efêmeras de apreensão do espaço urbano através da proposta de novos procedimentos como a psicogeografia e novas práticas como a deriva, construindo outra comunicação na cidade por modos que expressam uma cultura urbana de expressões múltiplas, revelando-a.

Nessa esteira, os situacionistas foram um dos primeiros grupos "[...] a criticar de forma radical o movimento moderno em arquitetura

Movimento, Porto Alegre, v. 17, n. 01, p. 237-251, janeiro/março de 2011. 
e urbanismo, principalmente seus maiores símbolos, o funcionalismo separatista da Carta de Atenas e a racionalidade cartesiana de seu maior defensor, Le Corbusier" (JACQUES, 2003, p. 14), ao opor-se à petrificação do espaço urbano e uma consequente museificação e patrimonialização dos centros históricos. Para eles, o caminhar na cidade possibilita(va) criar uma narrativa da exploração das muitas cidades que existem em uma metrópole e, a partir dela, construíam mapas que traduziam uma organização afetiva ditada pela experiência da deriva (FONSECA, 2008), pois, segundo eles:

\footnotetext{
As grandes cidades são favoráveis à distração que chamamos de deriva. A deriva é uma técnica de andar sem rumo. Ela se mistura à influência do cenário. [...] A arquitetura deve se tornar apaixonante. [...] A valorização dos lazeres não é uma brincadeira. Nós insistimos que é preciso inventar novos jogos. (DEBORD; FILLON, 1954. apud JACQUES, 2003, p. 17)
}

Tal prática surge por oposição a essas cidades-espetáculo que marcavam uma urbe estática e pouco convidativa à participação e criação. Para eles, a construção de situações seria a realização contínua de um grande jogo.

\section{GEOCACHING: CONSTRUINDO SITUAÇÕES COM JOGOS URBANOS BASEADOS EM GEOLOCALIZAÇÃo (GPS)}

Geocaching é um jogo de caça ao tesouro hightech presente em mais de 200 países, no qual jogadores equipados de dispositivos móveis com GPS ${ }^{5}$ (SISTEMA, 2010) buscam recipientes escondidos (geocaches) (WEBB, 2001) em espaços públicos por meio de coordenadas de geolocalização para, em seguida, compartilhar esta experiência online. Esta modalidade de jogo surgiu quando, em maio de 2000, o governo dos EUA liberou o acesso civil ao GPS.

\footnotetext{
${ }^{5}$ O Sistema de Posicionamento Global (do original inglês Global Positioning System ou do português "Geo-Posicionamento por Satélite"), inclui um conjunto de satélites e é um sistema de informação eletrônico que fornece via rádio a um aparelho receptor móvel a posição do mesmo com referencia às coordenadas de latitude e longitude. Saiba mais: http://pt.wikipedia.org/wiki/ Sistema_de_Posicionamento_Global Acesso em: 26 abr 2010.

Movimento, Porto Alegre, v. 17, n. 01, p. 237-251, janeiro/março de 2011.
} 
Pessoas começaram a testar a precisão dos receptores GPS. Dave Ulmer (membro de uma lista usenet sci.geo.satellite-nav) colocou um container em Portland, Oregon, e registrou suas coordenadas em um site. O recipiente foi encontrado pelos usuários do site, marcando sua visita tanto no logbook (diário de notas) quanto no ambiente online. Há mais de 2,7 milhões de jogadores registrados, crescendo a uma taxa de 2.500 novos registros por dia em 2009 (FARMAN, 2009).

Existem atualmente 850 mil geocaches escondidos em todo o mundo (incluindo Antártica). Uma vez que os jogadores encontram a cache, assinam seu nome de jogador no logbook, juntamente com a data da descoberta. Esta assinatura física é uma exigência do jogo, para provar a sua presença no cache. Assim, este jogo de caça ao tesouro com GPS coloca em relação o espaço físico com o ciberespaço, evidenciando um espaço híbrido, uma realidade mista, de presença-ausência. Essa nova configuração de jogo vai disseminar práticas de nomadismo tecnológico, ao transformar o espaço público em cenário de jogo, já que o movimento na cidade é condição para sua existência, remetendo à ideia de deriva ou psicogeografia de Guy Debord. Segundo Leão (2004, p. 9) “a psicogeografia, proposta pelos situacionistas, no final dos anos 50, busca resgatar e redescobrir ligações entre os conteúdos afetivos e os espaços públicos, como registro da experiência de deambular, à deriva". A inserção das novas tecnologias (nômades) causa profundas modificações na relação com o espaço, nas formas sociais e práticas culturais. Essas errâncias urbanas representam um tipo específico de apropriação do espaço público, que não foi pensando nem planejado pelos urbanistas, segundo Jacques (2006).

Nesse sentido, o geocaching, como prática cultural, originada da convergência entre jogos populares e as tecnologias móveis, funcionam como estímulo aos novos e velhos rituais sociais: trocas, informações, cooperação, reforço da coesão, estimulando um capital social, ou seja, mecanismos de confiança, de reciprocidades, compartilhamento de normas e valores pelas redes, dados a convergência entre elementos tradicionais, como o jogo caça ao tesouro com as novas tecnologias de informação e comunicação contemporâneas (LEMOS, 2007b). Esta prática cultural, portanto, possui grande

Movimento, Porto Alegre, v. 17, n. 01, p. 237-251, janeiro/março de 2011. 
capacidade de socialidade e subjetivação, pelas suas próprias características de deriva, descobertas e partilha de experiência.

Alguns passos para perseguir esta aventura incluem: o aprendizado do funcionamento do GPS; o registro da conta no site geocaching.com; a seleção de um cache, a partir das dificuldades de localização e de terreno, segundo o nível de experiência do grupo; a ação de esconder caches; o registro de suas coordenadas; a descoberta de uma nova cache, a assinatura no seu logbook, a ação de levar algo do cache e deixar algo no seu lugar (regra do jogo); o retorno para casa e compartilhamento desta experiência com os demais jogadores no site geocaching.com.

Segundo o site organizador do jogo ${ }^{6}$ (GROUNDSPEAK, 2009), as variações do geocaching incluem as diferentes formas dos recipientes: geocache tradicional, multicache, puzzle, cache-evento ou Cache In Trash Out Event. Quanto ao aspecto da dificuldade para localização e de acesso ao terreno, os níveis variam de 1 a 5 , crescendo da menor para a maior dificuldade. Há um guia de uso no site no qual orienta que os geocaches devem ser guardados em lugares seguros; recomenda-se que não se coloque alimentos, explosivos ou objetos cortantes nos recipientes.

Como uma prática cultural de aventura, o geocaching não está alicerçado exclusivamente pelo discurso da busca pela natureza ou pelo interesse na vida saudável, pois traz na mobilidade urbana a sua maior motivação, o que leva à deriva, descobertas e uma experiência compartilhada.

No lugar de uma relação enérgica (COELHO
DOS SANTOS, 1997), comum às modalidades do
esporte moderno (às quais correspondem noções
como destreza muscular, força, potência, busca
de resultados e performances, recordes, etc.), o
que parece evidenciar-se na vivência das práticas
corporais de aventura é uma relação estética com
o corpo e com os elementos da natureza, os quais
interagem no plano das ressonâncias, do estilo,

${ }^{6}$ Confira em: http://www.geocaching.com/, site mantido pela Groundspeak, Inc. A versão em português está em: http://www.geocachingbrasil.com.br/

Movimento, Porto Alegre, v. 17, n. 01, p. 237-251, janeiro/março de 2011. 
da ludicidade, das composições e negociações. (VILLAVERDE, 2003, p. 67) ${ }^{7}$

Corroboro com Villaverde (2003), ao enfatizar tal experiência como prática cultural, sendo necessário compreender seus significados partilhados, para além das suas motivações restritas ao benefício físico ou pela característica competitiva típica dos esportes modernos.

\title{
4 ConsideraçõES FINAIS
}

A vivência desta experiência de jogo coloca em questão as possibilidades lúdicas por meio destas novas tecnologias, assim como apontam novas formas de apropriação urbana e a conformação de uma nova cultura urbana e de jogo. Compreender essa dinâmica é fundamental para uma visão mais profunda do complexo processo comunicacional contemporâneo. Espera-se que este trabalho possa dar visibilidade ao jogo e agregar novos participantes; estimular novas pesquisas e novas práticas no ambiente urbano, incentivar a deriva e promover encontros mediados (ou não) por meio desta aventura.

\begin{abstract}
Por meio de noções, ou metáforas, como orgia, socialidade, tribo, emoção, estética, pretendo mostrar que o laço social não é mais unicamente contratual, racional, simplesmente utilitário ou funcional, mas contém uma boa parte de não-racional, de não lógico, algo que se exprime na efervescência de todas as formas ritualizadas (esporte, música, canções, consumo, consumição, revoltas, explosões sociais) ou, em geral, totalmente espontâneas. (MAFFESOLI, 2005, p. 7)
\end{abstract}

O que o autor parece nos indicar com esta passagem é a ideia de religação, comum em diversas experiências efêmeras das quais promovem relações, marcam um espaço, favorecem conexões. Assim, os jogos urbanos dos dispositivos móveis parecem ampliar

${ }^{7}$ COELHO DOS SANTOS, Francisco C. Controle e contrato: duas formas de relação com a alteridade. Revista Educação, Subjetividade e Poder, Porto Alegre, v. 4, n. 4, 1997

Movimento, Porto Alegre, v. 17, n. 01, p. 237-251, janeiro/março de 2011. 
possibilidades de experimentar formas renovadas de sociabilidade e subjetividade. Para o autor, em processos de massificação constante acontecem condensações e organizam-se tribos mais ou menos efêmeras que comungam valores minúsculos e, num balé sem fim, chocam-se, atraem-se e repelem-se numa constelação de contornos mal definidos e totalmente fluidos. E esta parecer ser uma das principais características das sociedades pós-modernas.

Dessa forma, se o principal antídoto contra o espetáculo das cidades pode estar na sua apropriação e (re)criação pelos sujeitos, acredito na construção de outra cultura urbana, repleta de situações (jogos, deambulações, derivas) e desvios, apoiada pela assertiva de Jacques (2003, p. 13):

O interesse dos situacionistas pelas questões urbanas foi uma conseqüência da importância dada por estes ao meio urbano como terreno da ação, de produção de novas formas de intervenção e de luta contra a monotonia, ou ausência de paixão, da vida cotidiana moderna. A crítica urbana situacionista permanece assim, em sua essência, pertinente.

Pensar, portanto, a inclusão pela aventura, seja no urbano ou na natureza, permanece uma questão central e atual, carecendo de novos estudos, pesquisas e análise sobre onde e como podemos coletar elementos para uma educação para/pelo lazer na cidade, considerando-o como campo possível de contra-hegemonia, pois só assim faz sentido pensar nos seus aspectos educativos.

Movimento, Porto Alegre, v. 17, n. 01, p. 237-251, janeiro/março de 2011. 


\begin{abstract}
Mobility as adventure in the city: games based on geolocation (gps) and appropriation urban.

Abstract. This article proposes thinking on the relationship of a new mode of play and public space through cultural practices that uses technologies of devices mobile. When weaving interdisciplinary relationships between the field of leisure, communication studies and space sought to recognize experiments, beyond the mere consumption of ecologically correct speech and / or the utility of physical activity as a promoter of healthy habits, inserting the mobility of games urban, as cultural practices that provide for the sharing of experience, offering new forms of sociability and appropriation as leisure in contemporary.
\end{abstract}

Keywords. Leisure activities. Cities. Play and playthings

Movilidad como en la aventura de la ciudad: juegos basados en geolocalización (gps) y apropiación urbana.

Resumen. En este ensayo se reflexiona sobre la relación de un nuevo modo de juego y espacios públicos a través de prácticas culturales que utilizan la tecnología de los dispositivos móviles. Al tejer relaciones interdisciplinarias entre el campo del ocio, los estudios sobre comunicación y el espacio trató de reconocer las experiencias, más allá del mero consumo de expresión ecológicamente correctos y / o la utilidad de la actividad física como un promotor de hábitos saludables, en la inserción de el juego urbano de movilidad, como las prácticas culturales que prevén el intercambio de experiencias, ofreciendo nuevas formas de sociabilidad y de los créditos del tiempo libre en la cultura urbana contemporánea

Palabras clave: Atividades recreativas. Ciudades. Juego y implementos de juegos.

\title{
REFERÊNCIAS
}

BENTHAM, Jeremy; SILVA, Tomaz Tadeu da; MILLER, Jacques-Alain; PERROT, Michelle; WERRET, Simon. O Panóptico. Belo Horizonte: Autêntica, 2008.

COMITÉ GESTOR DA INTERNET NO BRASIL. Centro de Estudos sobre as Tecnologias da Informação e da Comunicação (CETIC). Pesquisa sobre o Uso das Tecnologias da Informação e da Comunicação no Brasil: TIC Domicílios e TIC Empresas 2009. São Paulo, 2009. Disponível em: http://www.cetic.br/usuarios/ tic/2009/index.htm Acesso em: 26 abr 2010.

Movimento, Porto Alegre, v. 17, n. 01, p. 237-251, janeiro/março de 2011. 
FARMAN, Jason. Locative Life: Geocaching, Mobile Gaming, and Embodiment. UC Irvine: Digital Arts and Culture 2009. Disponível em:http://www.escholarship.org/uc/ item/507938rr Acesso em: 15 abr 2010.

FONSECA, Cláudia Graça da. A cidade em comunicação: paisagens, conversas e derivas no Centro de BH. 2008. Dissertação. Programa de Pós-Graduação em Comunicação Social, Universidade Federal de Minas Gerais, Belo Horizonte, 2008.

FRAGA, Alex. Branco. Anatomias emergentes e o bug muscular: pedagogias do corpo no limiar do século XXI. In: SOARES, Carmen Lúcia. (Org.). Corpo e História. 3 ed. Campinas: Autores Associados, 2006a. p. 61-77.

Exercício da informação: governo dos corpos no mercado da vida ativa. Campinas: Autores Associados, 2006b.

GROUNDSPEAK. A guide to geocaching. 2009. Disponível em: http://www.geocaching.com/articles/Brochures/EN/EN_Geocaching_BROCHURE_online_bw.pdf . Acesso em: 12 abr 2010.

JACQUES, Paola Berenstein. Elogio aos errantes. In: JEUDY, Henri Pierre; JACQUES, Paola Berenstein. Corpos e cenários urbanos: territórios urbanos e políticas culturais. Salvador: EDUFBA, 2006. p. 117-140.

JACQUES, Paola Berenstein; ABREU, Estela dos Santos. Apologia da deriva: escritos situacionistas sobre a cidade. Rio de Janeiro: Casa da Palavra, 2003.

LEÃO, Lúcia (Org). Derivas: cartografias do ciberespaço. São Paulo: Annablume, SENAC, 2004.

LEMOS, André. Cibercultura e mobilidade: a era da conexão. In: LEÃO, Lúcia (org). Derivas: cartografias do ciberespaço. São Paulo: Annablume, SENAC, 2004. p. 17-44.

LEMOS, André. Ciberespaço e Tecnologias Móveis: processos de Territorialização e Desterritorialização na Cibercultura. In: MÉDOLA, Ana Silvia; ARAÚJO, Denise; BRUNO, Fernanda. (org). Imagem, Visibilidade e Cultura Midiática. Porto Alegre: Sulina, 2007a. p. 277-293.

LEMOS, André. Comunicação e práticas sociais no espaço urbano: as características dos Dispositivos Híbridos Móveis de Conexão Multirredes (DHMCM Revista Comunicação, Mídia e Consumo, São Paulo, v.4, n.10, p.23-40, jul 2007b.

Cultura da Mobilidade. Revista Famecos, Porto Alegre, v.1, n. 40, p. 28-35, 2009.

Mídia Locativa e Território Informacional. In: ARANTES, Priscila; SANTAELLA, Lúcia. Estéticas tecnológicas: novos modos de sentir. São Paulo: EDUC/SP, 2008.

MAFFESOLI, Michel. O mistério da conjunção: ensaios sobre comunicação, corpo e socialidade. Porto Alegre: Sulina, 2005.

Michel. Sobre o nomadismo: vagabundagens pós-modernas. Rio de Janeiro: Record, 2001.

Movimento, Porto Alegre, v. 17, n. 01, p. 237-251, janeiro/março de 2011. 
NIEMEYER, Carlos Augusto da Costa. Parques Infantis de São Paulo: lazer como expressão de cidadania. São Paulo: Annablume: FAPESP, 2002.

PEREIRA JUNIOR, Aurélio da Cunha. Wireless Street Games: comunicação, tecnologia sem fio e cidades. 2006. Monografia. Faculdade de Comunicação, Universidade Federal da Bahia, Salvador, 2006.

PRIGGE, Walter. Metropolização. In: PALLAMIN, Vera M. Cidade e Cultura: esfera pública e transformação urbana. São Paulo: Estação Liberdade, 2002. p. 51-58.

SANTOS, Laymert Garcia dos. São Paulo não é mais uma cidade. In: PALLAMIN, Vera M. Cidade e Cultura: esfera pública e transformação urbana. São Paulo: Estação Liberdade, 2002. p. 111-116.

SISTEMA DE POSICIONAMENTO GLOBAL. In: WIKIPÉDIA, a enciclopédia livre. Flórida: Wikimedia Foundation, 2010. Disponível em: <http://pt.wikipedia.org/w/ index.php?title=Sistema_de_Posicionamento_Global\&oldid=19794761>. Acesso em: 26 abr. 2010.

VILLAVERDE, Sandoval. Refletindo sobre lazer/turismo na natureza, ética e relações de amizade. In: MARINHO, Alcyane; BRUHNS, Heloisa Turini. Turismo, lazer e natureza. Barueri, SP: Manole, 2003. p. 53-74.

WEBB, Robert. Recreational Geocaching: The South East Queensland Experience. In: A Spatial Odyssey Australian Surveying Congress. Brisbane, Sept. 2001. Disponível em: http://eprints.qut.edu.au/4160/ Acesso em: 12 abr. 2010. 